\title{
Estudo de viabilidade da cama de aviário peletizada não compostada como adubo orgânico
}

O Brasil é um dos maiores produtores de aves de corte do mundo, como consequência gera toneladas de resíduos que podem causar inúmeros impactos ambientais, entretanto os nutrientes presentes nesse resíduo podem apresentar resultados satisfatórios em atividades agronômicas. Neste contexto o presente trabalho teve por objetivo estudar da viabilidade do uso da cama de frango peletizada não compostada como adubo orgânico. Análises de caracterização físicoquímicas foram realizadas, a fim de avaliar os teores de nutrientes em camas de frango com diferentes ciclos de criação de aves para determinar o melhor materia possível para a produção de pellets de cama de frango. Posteriormente foram realizados testes agronômicos para estudo da atividade agronômica do composto em estudo, por fim foram realizadas análises foliares para a quantificação de nutrientes absorvidos pelo cultivo da cultura do milho (Zea mays) em sistemas adubados com o pellet de cama de frango e sistemas adubados com adubo mineral para comparação. Os valores encontrados para os nutrientes $P$, $K$ e principalmente $\mathrm{N}$ são satisfatórios, se enquadrando dentro dos valores determinados pela legislação (BRASIL-MAPA) e sempre próximos aos valores citados na literatura. Os resultados obtidos nos testes agronômicos mostram uma boa atividade agronômica, onde pudemos ver uma significativa vantagem no crescimento do milho cultivado em solo tratado com o pellet de cama de frango em relação ao crescimento do milho sem adubação e uma pequena inferioridade em relação ao cultivo em solo adubado com adubo mineral. A análise foliar em alguns casos mostrou uma maior absorção de alguns nutrientes em cultivos do milho com a adubação orgânica. Assim concluímos que a utilização de cama de frango peletizada não compostada como adubo apresenta bons resultados no cultivo de culturas como o milho (Zea mays)

\section{Viability study of the bed of poultry not composted pellet as organic fertilizer}

\begin{abstract}
Brazil is one of the largest producers of poultry in the world, as a consequence generates tons of waste that can cause numerous environmental impacts, however the nutrients present in this residue can present satisfactory results in agronomic activities. In this context, the objective of this study was to study of the viability of the use of non-compost pellet poultry as an organic fertilizer. Physical-chemical characterization analyzes were carried out in order to evaluate the nutrient content in chicken litters with different breeding cycles to determine the best possible material for the production of chicken bed pellets. Afterwards, agronomic tests were performed to study the agronomic activity of the compound under study. Finally, foliar analyzes were performed to quantify nutrients absorbed by maize (Zea mays) cultivation in systems fertilized with chicken bed pellets and fertilized systems With mineral fertilizer for comparison. The values found fo nutrients $\mathrm{P}, \mathrm{K}$ and mainly $\mathrm{N}$ are satisfactory, being within the values determined by the legislation (BRASIL-MAPA) and always close to the values quoted in the literature. The results obtained in the agronomic tests show a good agronomic activity, where we could see a significant advantage in the growth of the maize grown in soil treated with the chicken bed pellet in relation to the growth of corn without fertilization and a small inferiority in relation to the cultivation in only fertilized with mineral fertilizer. Leaf analysis in some cases showed a higher uptake of some nutrients in maize crops with organic fertilization. Thus, we conclude that the use of a bed of pelleted chicken not composted as fertilizer has good results in the cultivation of crops such as maize (Zea mays).
\end{abstract}

Keywords: Chicken bed; Pellet; Uncooked; Agronomic activity; Maize (Zea mays)

Topic: Desenvolvimento, Sustentabilidade e Meio Ambiente

Reviewed anonymously in the process of blind peer.
Received: $\mathbf{1 1 / 0 7 / 2 0 2 0}$

Approved: 24/10/2020
Nelson Consolin Filho (iD)

Universidade Tecnológica Federal do Paraná, Brasil

http://lattes.cnpq.br/5820606948533146

http://orcid.org/0000-0002-4847-0701

consolin@utfpr.edu.br

\section{Aléx Junior Barbosa de Faria (ib}

Universidade Tecnológica Federal do Paraná, Brasil

http://lattes.cnpq.br/8308936611321119

http://orcid.org/0000-0001-6018-5025

alexir.farias@gmail.com

Marcilene Ferrari Barriquello Consolin (iD)

Universidade Tecnológica Federal do Paraná, Brasil

http://lattes.cnpq.br/3028205116451785

http://orcid.org/0000-0001-5499-2701

marcilenef@utfpr.edu.br

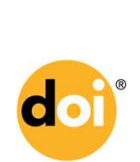

DOI: 10.6008/CBPC2237-9290.2020.003.0015

\author{
Marcos Antônio Piza (D) \\ Universidade Tecnológica Federal do Paraná, Brasi \\ http://lattes.cnpq.br/2278867979291401 \\ http://orcid.org/0000-0002-2650-7622 \\ mapiza@gmail.com \\ Estela dos Reis Crespan (iD \\ Universidade Tecnológica Federal do Paraná, Brasil \\ http://lattes.cnpq.br/5093731613842088 \\ http://orcid.org/0000-0003-4802-8574 \\ ercrespan@gmail.com
}

Referencing this:

CONSOLIN FILHO, N.; FARIAS, A. J. B.; CONSOLIN, M. F. B.; PIZA, M. A.; CRESPAN, E. R.. Estudo de viabilidade da cama de aviário peletizada não compostada como adubo orgânico. Natural Resources, v.10, n.3, p.145-161, 2020. DOI: http://doi.org/10.6008/CBPC2237$\underline{9290.2020 .003 .0015}$ 


\section{INTRODUÇÃO}

Desde a descoberta do Brasil o frango é utilizado como alimento, entretanto apenas a partir de meados do século XX que produções em grande escala começaram a se estruturar a nível comercial, o que ocorreu principalmente devido as novas possibilidades de melhoramento genético, assim como um maior investimento na estrutura de criação e abate. Na década de 90 a produção aviária deu um salto decisivo para a integração no mercado mundial, graças à abertura da economia latino-americana, da reorganização e reestruturação da base agroindustrial da cadeia produtiva do frango e o aumento per capta de consumo de frango.

No entanto, assim como toda atividade humana de produção, a avicultura também gera resíduos (OVIEDO-RONDÓN, 2008). Com a grande produção de aves de corte, surgem resíduos na forma de esterco, efluentes, camas e aves mortas. Estes resíduos possuem concentrações importantes de nitrogênio, fósforo, potássio, minerais traço como cobre e zinco, e uma alta carga de bactérias (TERZICH et al., 2000). Porém, a rápida decomposição destes resíduos, dentro e fora dos lugares de produção avícola, pode afetar a qualidade do ar, devido à produção de muito pó, emissões de gases como amônia, exalação de odores, pequenas quantidades de sulfeto de hidrogênio, e outros compostos orgânicos voláteis que aumentam os odores e, além disso, a incineração de carcaças de aves mortas libera dióxido sulfuroso, oxido nítrico, cinzas e odores (ROBARGE et al., 1999; ZHONGCHAO et al., 2004; LACEY et al., 2004; WILLIAMS et al., 1999; SEIFFERT et al., 2000).

Cama de frango, também conhecida como cama de aviário, consiste de uma mistura de materiais vegetais onde os mais utilizados são as serragens, palhadas e maravalhas (raspas de madeira), podendo ser a cama de frango constituída de apenas um desses materiais ou de uma mistura. Este material tem a função de absorção da umidade, diluição de uratos e fezes, isolamento térmico, além de proporcionar uma superfície macia para as aves, evitando a formação de calo no peito (HERNANDES et al., 2002).

Para se falar em impacto ambiental é necessário primeiro defini-lo. Segundo o art. $3^{\circ}$ da lei federal no 6.938 de 1981, Lei da Política Nacional do Meio Ambiente, é "o conjunto de condições, leis, influências e interações de ordem física, química e biológica, que permite, abriga e rege a vida em todas as suas formas". Já a Resolução CONAMA 01/86 define impacto ambiental como:

(...) qualquer alteração das propriedades físicas, químicas e biológicas do meio ambiente, causada por qualquer forma de matéria ou energia resultante das atividades humanas que, direta ou indiretamente afetem: $\mathrm{i}$ - a saúde, a segurança e o bem-estar da população; ii - as atividades sociais e econômicas; iii - a vida; iv - a qualidade dos recursos ambientais. (...)

A partir do final do século XX a atividade avícola no Brasil dá um grande salto, de mãos dadas com a grande produção de aves vem os grandes criadouros de aves, gerando uma grande quantidade de resíduos, formado pela cama de frango, constituída de palhas, serragens, fezes, resto de ração e animais mortos. Esses resíduos contêm quantidades consideráveis de alguns elementos como o nitrogênio, cálcio, magnésio e fósforo.

Ao se falar em impacto ambiental, a primeira coisa que vem em mente é algo ruim, prejudicial, porém impacto ambiental é qualquer alteração, nas propriedades químicas, físicas e biológicas do meio ambiente, 
se não tomado os devidos cuidados no manejo desses resíduos, os mesmos podem poluir águas superficiais e lençóis freáticos, podem aumentar os nutrientes minerais, as substâncias orgânicas que demandam oxigênio, materiais em suspensão e em algumas situações micro-organismos patogênicos (SEIFFERT, 2000), mas se tomado os devidos cuidados no manejo a cama de frango pode ter algumas reutilizações favoráveis econômica e ambientalmente.

É comum o uso de cama de frango como adubo, tanto em hortas de fundo de quintal ou até mesmo em grandes plantações. A grande concentração de certos nutrientes sendo os mais significativos fósforo (P), magnésio $(\mathrm{Mg})$, potássio $(\mathrm{K})$, carbono $(\mathrm{C})$ e o mais evidente o nitrogênio $(\mathrm{N})$ são os principais responsáveis pelo potencial de adubação da mesma.

O cultivo de plantas sejam elas tanto geradoras de grãos quanto de pastagem implicam na disponibilidade de nutrientes em quantidade suficiente ou equilibrada para o seu desenvolvimento produtivo. O manejo de produção de aves é baseado na alimentação de concentrados, porém apenas uma pequena porcentagem deste concentrado é metabolizada e utilizada no desenvolvimento das aves, a maior parte é eliminada pelas fezes e urina.

Devido à grande disponibilidade em matéria orgânica e nutriente a cama se mostra com grande potencial agronômico. Os benefícios alcançados pela utilização da cama de frango como adubo, além de químicos pela significativa concentração de macro e micronutrientes, são também físicos pois a matéria orgânica ajuda a diminuir a compactação do solo e ainda retém umidade.

Em função de seu potencial de fertilização, preservação do solo e do seu baixo custo a cama de frango se torna fundamental para o desenvolvimento de culturas agrícolas. Segundo Lima et al. (2007) analisando a influência da cama de frango como adubo em Latossolo Vermelho Distrófico o mesmo se mostra de grande importância na complementação e equilíbrio de nutrientes químicos.

A cama de aviário possui uma grande concentração de elementos que são denominados como macro e micronutrientes, esses nutrientes são essenciais para o pleno desenvolvimento de plantas, entretanto a maior parte desses nutrientes está na forma orgânica, forma não adequada para absorção pelas plantas, apenas o nitrogênio inorgânico $\left(\mathrm{N}_{\mathrm{i}}\right)$ é absorvido pelas plantas. A alternativa mais utilizada para diminuir esse problema é a compostagem, o processo é relativamente simples em termos industriais, porém existe o fator negativo "tempo", que para uma produção comercial de grande escala de adubo orgânico e organomineral levaria a alguns déficits de produção (LANA, 2009; BENITES, 2010).

A cama de frango se apresenta como uma boa opção em processos de adubação. Nos últimos anos o material vem ganhando certo destaque, porém sua utilização ainda é extremamente baixa em comparação com produtos convencionais. De todo o volume de fertilizante de base orgânica (orgânico e organomineral) produzido no país, apenas uma pequena parcela é destinada a grãos e fibras. A pouca utilização por esse segmento pode ser atribuída à baixa concentração de nutrientes em relação a fertilizantes químicos e às características físicas do produto, uma vez que a maior parte dos fertilizantes organominerais é comercializada na forma de farelo ou pó, fator este que dificulta a utilização de implementos agrícolas do tipo plantadeira (BENITES et al., 2010). 
Por ser rica em nutrientes e matéria orgânica a cama de frango pode ser utilizada para adubação de culturas, cada cultura tem suas especificidades quanto a sua necessidade de nutrientes, variando assim a quantidade de adubo para cada uma delas. Além das variações de quantidade de produto (cama de frango) necessário para cada cultura específica, existirá outra variação na quantidade de aplicação, porém essa dependerá das concentrações de nutrientes existentes na cama. Diferente de adubos químicos convencionais a cama é um resíduo constituído de uma mistura de maravalha, palhas entre outros como resto de ração, fezes, urina e resto de aves mortas, a concentração de nutrientes é muito variável neste tipo de composto.

Para ter conhecimento da quantidade de material que será necessário utilizar para adubação é preciso, além de conhecer a necessidade da cultura que está sendo cultivada, a concentração de cada nutriente existente na cama, ou seja, realizar uma marcha agronômica do material, com caracterizações físico-químicas e testes agronômicos de germinação e absorção de nutrientes (análise foliar) (MALAVOLTA, 1987; FAQUIN, 2005; PIRES et al., 2008).

\section{MATERIAIS E MÉTODOS}

O desenvolvimento deste trabalho previu a caracterização e aplicação da cama de frango no desenvolvimento da cultura de milho (Zea Mays). A cama de frango foi fornecida pela empresa Organmix Indústria e comércio de adubos e fertilizantes - ME, situada na Rod PR 467, Km 2, bairro Gleba Jaracatia, no município de São Tome/PR. Utilizou-se, amostras in natura e amostras peletizada de diferentes ciclos de utilização no aviário. A caracterização foi feita por meio de análises físico-químicas.

Para as análises físico-químicas utilizaram-se os seguintes procedimentos: Carbono orgânico (CO); Nitrogênio total (N); Potássio (K); Fósforo (P); Capacidade de Troca de Cátions (CTC). Posteriormente realizaram-se os testes agronômicos: Avaliação da germinação e desenvolvimento inicial de sementes de milho em sistema enriquecido com cama de frango peletizada; Caracterização da adsorção de nutrientes pelas plantas.

\section{Carbono orgânico (CO)}

A determinação do Carbono foi realizada se utilizando o método de Walkey \& Black, onde se colocou $0,5 \mathrm{~g}$ de amostra, previamente triturada em gral e passada em peneira de 80 mesh em erlenmeyer de 250 $\mathrm{mL}$. Pipetou-se $10 \mathrm{~mL}$ da solução de dicromato de potássio $0,2 \mathrm{~mol} \mathrm{~L}^{-1}$ e adicionou-se ao erlenmeyer com a amostra, no mesmo colocou-se um tubo de ensaio de $25 \mathrm{~mm}$ de diâmetro e $250 \mathrm{~mm}$ de altura, cheio de água e protegido com papel alumínio, na boca do erlenmeyer, onde funcionará como condensador. Aqueceu-se em placa de aquecimento até fervura branda durante 5 minutos. Posteriormente deixou-se esfriar, adicionou-se $80 \mathrm{~mL}$ de água destilada, $1 \mathrm{~mL}$ de ácido ortofosfórico e 3 gotas de indicador difenilamina a $10 \mathrm{~g}$ $\mathrm{L}^{-1}$. Titulou-se com solução de sulfato ferroso amoniacal $0,05 \mathrm{~mol} \mathrm{~L}^{-1}$. A viragem ocorre quando a cor azul desaparece dando lugar à verde. Anotou-se a quantidade de mililitros gastos. Efetuou-se uma prova em branco com $10 \mathrm{~mL}$ da solução de dicromato de potássio e anotou-se o volume de sulfato ferroso amoniacal 
gasto.

\section{Nitrogênio total (N)}

A determinação do teor de nitrogênio total foi realizada utilizando-se o método Kjedhal por destilação a vapor, onde se partiu de $0,7 \mathrm{~g}$ de cama de frango que foi transferido para um balão de $100 \mathrm{~mL}$, em seguida adicionou-se $15 \mathrm{~mL}$ de mistura ácida de sulfatos e procedeu-se a digestão fervendo o conteúdo até a completa destruição da matéria orgânica. Após resfriar, adicionou-se $25 \mathrm{~mL}$ de água e agitou-se para homogeneização, adicionou-se 2 gotas de solução xaroposa de cloreto férrico. Juntou-se gradativamente, solução de $\mathrm{NaOH}$ a $30 \%$ até que a solução apresente coloração castanho-claro, nesse momento se iniciou a formação dos compostos básicos de ferro.

Em paralelo adicionou-se $25 \mathrm{~mL}$ de solução de ácido bórico a $4 \%$ em erlenmeyer de $125 \mathrm{~mL}$, adicionou-se a esta solução 5 gotas do indicador misto (verde de bromocresol + vermelho de metila). A extremidade livre do destilador N - TE - 0363 Tecnal foi inserida na solução, estando imersa na solução até o fim da destilação. Adicionou-se então $2 \mathrm{~mL}$ de $\mathrm{NaOH} 30 \%$ e procedeu-se com a destilação da amônia a vapor durante 5 minutos. $\mathrm{O}$ volume destilado, depois de frio foi titulado com solução padronizada de $\mathrm{H}_{2} \mathrm{SO}_{4}$ $0,005 \mathrm{~mol} \mathrm{~L}^{-1}$, até a mudança da cor roxa ou azulada para rosa. Por fim realizou-se o teste com branco.

\section{Potássio (K)}

Para determinar o teor de Potássio nas amostras da cama de frango utilizou-se da Espectrometria de Absorção Atômica (EAA) da marca Analytik Jena, modelo NOVAA300. Onde se partiu de $40 \mathrm{~g}$ da amostra e transferiu-se para um béquer, adicionou-se $50 \mathrm{~mL}$ de água e $2 \mathrm{~g}$ de carvão ativo, ferveu-se por 10 minutos. Esfriou-se e filtrou-se à vácuo. Pipetou-se $2 \mathrm{~mL}$ e transferiu-se para balão volumétrico de $100 \mathrm{~mL}$, completouse o volume com água, para posterior leitura no EAA.

\section{Capacidade de troca de cátions (CTC)}

Pesou-se 2,00 g de cama de frango e 1,00 g de carvão ativo, transferiu-se para erlenmeyer de 250 $\mathrm{mL}$, no mesmo sistema juntou-se $100 \mathrm{~mL}$ de $\mathrm{HCl}$ 0,5 mol L-1 e agitou-se por 30 minutos. A amostra foi filtrada a vácuo. Lavou-se o retido com porções de água destilada, procedendo a uma nova lavagem só após todo o líquido da lavagem anterior ter sido drenado. Efetuou-se um número de lavagens suficiente para ter um volume de $350 \mathrm{~mL}$ no kitassato. Para cada amostra trocou-se o kitassato.

Transferiu-se $100 \mathrm{~mL}$ da solução de acetato de cálcio $0,5 \mathrm{M}$ para copo de 250 . Esse volume de solução foi distribuído por toda a superfície do material orgânico retido no funil de Büchner, em sucessivas porções de $15 \mathrm{~mL}$, sob vácuo. Adicionava-se uma nova porção da solução de acetato somente após a porção anterior ter sido totalmente drenada. Na sequência, lavou-se com porções de água até atingir um volume de aproximadamente $300 \mathrm{~mL}$ no kitassato. Titulou-se a amostra do kitassato com solução $0,1 \mathrm{~mol} \mathrm{~L}^{-1}$ de $\mathrm{NaOH}$ padronizada, empregando a solução de fenolftaleína como indicador. Conduziu-se uma prova em branco em 
duplicata, empregando o carvão ativado, sem a presença da amostra.

\section{Germinação das sementes e desenvolvimento inicial}

O experimento para germinação foi instalado em triplicatas para cama com sete ciclos de criação de aves. As sementes de milho (Zea Mays) foram implantadas em copo descartável com solo (vermiculita) enriquecida com cama de frango, com variações de concentração. A utilização da vermiculita visou a mínima influência do solo no desenvolvimento da planta, essa etapa do trabalho objetiva avaliar a capacidade agronômica (adubação) apenas da cama de frango, sem influência de outros, assim a vermiculita por se apresentar de forma inerte se torna uma ótima opção para esse teste, tendo influencia mínima. A avaliação da germinação foi feita 10 e 30 dias após o início da germinação para o primeiro lote, já para o segundo lote a avaliação ocorreu com 10 e 24 dias após o início da germinação.

A avaliação realizada nessa etapa envolveu a mensuração de plantas, a qual consiste de uma avaliação macroscópica, para uma avaliação mais específica realizou-se técnicas que avaliaram microscopicamente, sendo a alternativa utilizada para esse tipo de análise a avaliação da absorção de nutrientes pela planta.

\section{Absorção de nutrientes}

A avaliação da absorção de nutrientes pela cultura do milho foi baseada pela quantificação dos macronutrientes NPK. Na determinação de Nitrogênio (N) utilizou-se a técnica de Destilação-Titulação (Kjeldahl). Na determinação de Fósforo (P) utilizou-se a técnica de Espectrofotometria no Ultravioleta Visível com Azul-de-Molibdênio e por último para a determinação do Potássio (K) utilizou-se o EAA.

\section{Digestão $\mathrm{H}_{2} \mathrm{SO}_{4}+\mathrm{H}_{2} \mathrm{O}_{2}$ (Kjeldahl)}

Transferiu-se $100 \mathrm{mg}$ de amostra para tubo digestor e adicionou-se $1 \mathrm{~g}$ de mistura 1:1 de sais sulfato de potássio e de cobre, $3 \mathrm{~mL}$ de ácido sulfúrico e $1 \mathrm{~mL}$ de peróxido de hidrogênio $30 \%$. Colocou-se em bloco digestor, aqueceu-se lentamente até 350 C e manteve-se a essa temperatura até a obtenção de um liquido esverdeado. Esfriou-se e completou-se o volume até $50 \mathrm{~mL}$ de água. $\mathrm{O}$ procedimento distrito acima para digestão da amostra se aplica para a determinação dos três macronutrientes, NPK.

\section{Determinação de Fósforo (P)}

No procedimento pipetou-se $5 \mathrm{~mL}$ de solução digerida de $\mathrm{H}_{2} \mathrm{SO}_{4}$ em tubo de $30 \mathrm{~mL}$, adicionou-se 10 $\mathrm{mL}$ da solução diluída de molibdado de amônio, uma ponta de espátula de ácido ascórbico e agitou-se. Após 30 minutos efetuou-se a leitura no espectrofotômetro em $660 \mathrm{~nm}$. Para os cálculos de determinação utilizase a equação:

$$
P_{(g / k g)}=L . F_{p} \cdot 10
$$




\section{RESULTADOS E DISCUSSÃO}

\section{Caracterização físico-química da cama de frango}

\section{Carbono Orgânico (CO)}

O Método de Walkey \& Black utilizado, apesar de ser de simples execução apresenta boa exatidão na determinação de carbono orgânico, e está baseado na oxidação de carbono orgânico do solo através de íons dicromato em meio fortemente ácido, e a determinação da quantidade de íons $\mathrm{Cr}^{3+}$ reduzido é feita por titulação do dicromato em excesso com íons $\mathrm{Fe}^{2+}$, conforme as reações abaixo:

$$
\begin{aligned}
& 2 \mathrm{Cr}_{2} \mathrm{O}_{7}{ }^{2-}{ }_{\text {(aq) }}+3 \mathrm{CO}{ }_{(\mathrm{s})}+16 \mathrm{H}^{+}{ }_{\text {(aq) }} \rightarrow 4 \mathrm{Cr}^{3+}{ }_{\text {(aq) }}+3 \mathrm{CO}_{2} \text { (g) }+8 \mathrm{H}_{2} \mathrm{O}_{\text {(I) }} \\
& \mathrm{Cr}_{2} \mathrm{O}_{7}{ }^{2-}{ }_{\text {(aq) }}+6 \mathrm{Fe}^{2+}{ }_{\text {(aq) }}+14 \mathrm{H}^{+}{ }_{\text {(aq) }} \rightarrow 2 \mathrm{Cr}^{3+}{ }_{\text {(aq) }}+6 \mathrm{Fe}^{3+}{ }_{\text {(aq) }}+7 \mathrm{H}_{2} \mathrm{O}_{\text {(l) }}
\end{aligned}
$$

Na primeira equação, o dicromato reduzido equivale ao carbono orgânico presente na amostra do solo. Na segunda equação, o excesso de dicromato é titulado com íons $\mathrm{Fe}^{2+}$ (solução padronizada de sulfato ferroso amoniacal - Sal de Mohr). Desta forma, a determinação de carbono orgânico total é feita pela diferença entre a quantidade de $\mathrm{Fe}^{2+}$ gasta na titulação, quando o $\mathrm{Cr}^{6+}$ foi adicionado, e aquela gasta na titulação do dicromato que restou após a oxidação do carbono da amostra - assumindo que todo o carbono da matéria orgânica está no estado de oxidação zero (BELTRAME, 2014).

Ao se analisar as amostras dos diferentes ciclos pode-se observar um aumento significativo nas quantidades de carbono orgânico conforme aumenta o número de ciclos de criação de aves (Tabela 1), exceto a cama com seis ciclos que apresenta valores menores do que todas as outras camas.

Tabela 1: Quantidades de CO encontrados na cama de frango em diferentes ciclos de criação de aves.

\begin{tabular}{l|l}
\hline \hline AMOSTRA & $\%$ CO \\
\hline \hline Cinco ciclos & $15,66-15,36$ \\
\hline Seis ciclos & $14,04-13,56$ \\
\hline Sete ciclos & $16,05-16,08$ \\
\hline Sete ciclos (pellet) & $16,38-15,96$ \\
\hline \hline
\end{tabular}

Os resultados obtidos foram satisfatórios, os valores se enquadraram dentro da legislação pertinente (BRASIL-MAPA) que permite um mínimo de $8 \%$ de $\mathrm{CO}$ em adubos orgânicos. Entretanto esses valores encontrados estão abaixo de valores citados na literatura. Orrico Júnior (2010), por exemplo, encontrou teores de $\mathrm{CO}$ que alcançaram 22,25\%, um pouco acima dos valores apresentados neste trabalho. Essa diferença pode ter relação com a compostagem, visto que o processo de umidificação (uma etapa da compostagem) faz com que a matéria orgânica apresente maior teor de carbono conforme avança a compostagem, como o material estudado neste trabalho não passa por compostagem é muito provável que apresente teores menores de carbono do que os valores citados na literatura, que são para cama compostada.

\section{Nitrogênio Total (N)}

Desenvolvida em 1883, a análise de nitrogênio de Kjeldahl é um dos métodos mais amplamente utilizados para a determinação de nitrogênio em substâncias orgânicas. As proteínas são os principais 
constituintes contendo nitrogênio na alimentação. A maioria das proteínas contém em torno de $16 \% \mathrm{~m} / \mathrm{m}$ de nitrogênio (HARRIS, 2012).

A Tabela 2 a seguir demonstra os quantitativos de $\mathrm{N}$ em diferentes ciclos de cama de frango. possível observar a ocorrência de um aumento nas concentrações entre as camas in natura, da cama com cinco ciclos até a cama com sete ciclos, já o pellet, produzido a partir da cama com sete ciclos, apresenta uma quantidade de Nitrogênio abaixo do valor da cama com seis e sete ciclos in natura. Tal resultado pode ter relação com a alta temperatura do processo de peletização.

Os valores encontrados foram satisfatórios, estando dentro dos valores descritos pela legislação pertinente (BRASIL-MAPA) que impõe pelo menos 2\%. Autores como Orrico Júnior (2010) e Bueno (2008) relatam diferentes valores de Nitrogênio para um composto de cama de frango, teores de Nitrogênio da ordem de $2,41 \%$ e acima de $3 \%$ respectivamente. Bueno (2008) é quem apresenta valores mais próximos dos apresentados neste trabalho, onde camas in natura chegam a apresentar teores de $\mathrm{N}$ acima de $6 \%$ e produto de maior interesse, o pellet, produzido a partir da cama com sete ciclos in natura apresentou valores acima de $4 \%$ de $\mathrm{N}$, é notório a queda do $\mathrm{N}$ após o processo de peletização, entretanto os valores finais do produto, mesmo apresentando essa queda, são satisfatórios.

Tabela 2: Quantitativo de N encontrado na cama de frango em diferentes ciclos de criação de aves.

\begin{tabular}{l|l}
\hline \hline AMOSTRA & \% NITROGÊNIO \\
\hline \hline Cinco ciclos & $3,88-3,99$ \\
\hline Seis ciclos & $5,87-6,15$ \\
\hline Sete ciclos & $6,37-6,77$ \\
\hline Sete ciclos (pellet) & $4,10-4,15$ \\
\hline \hline
\end{tabular}

\section{Potássio (K)}

As medidas da concentração de potássio presente nas amostras de cama de frango foram realizadas por meio da Espectrofotometria de Absorção Atômica (EAA) (SKOOG, 2009).

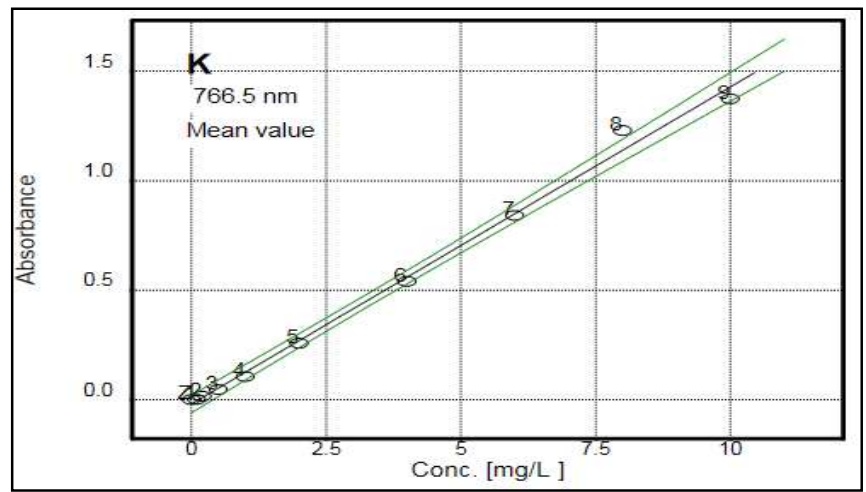

Figura 1: Curva de calibração utilizada para determinação de K em cama de frango.

A curva de calibração obtida é apresentada na Figura 1, cujo coeficiente de correlação foi de 0,9936, e a Tabela 3 mostra os valores de potássio encontrados na cama de frango em diferentes ciclos. Os teores de potássio encontrados estão bem abaixo dos valores mínimos mencionados pela legislação pertinente, onde sita $2 \%$ de $\mathrm{K}$ em um adubo orgânico, os resultados podem estar relacionados com erros no procedimento experimental, o mesmo apresenta uma elevada quantidade de diluições, ou ainda o próprio processo de 
extração do potássio da amostra pode não ter apresentado bons resultados influenciando diretamente as concentrações de potássio na análise final.

Tabela 3: Concentração de potássio encontrado na cama de frango com diferentes ciclos de criação de aves.

\begin{tabular}{l|l}
\hline \hline AMOSTRA & $\mathbf{K}{\left.\mathbf{~ ( ~} \mathbf{~ k g}^{-1}\right)}^{-1}$ \\
\hline \hline Cinco ciclos & $1,5-1,8$ \\
\hline Seis ciclos & $2,4-2,6$ \\
\hline Sete ciclos & $2,5-2,8$ \\
\hline Sete ciclos (pellet) & $2,2-2,5$ \\
\hline \hline
\end{tabular}

\section{Capacidade De Troca De Cátions (CTC)}

Existe uma grande variação de valores de CTC considerados bons para um composto como a cama de frango. Pereira Neto (2007) relata valores de 1000 - 3000 mmolc. $\mathrm{kg}^{-1}$. Outros estudos vêm relatando valores um pouco menores, que variam entre $600-800$ mmolc. $\mathrm{kg}^{-1}$ (KIEHL, 2004) e de $550-900 \mathrm{mmolc.kg}$ 1.

Tabela 4: Volume gasto de $\mathrm{NaOH}$.

\begin{tabular}{|c|c|}
\hline AMOSTRA & $\mathrm{V}(\mathrm{mL})$ \\
\hline Cinco ciclos & $13,9-14,1$ \\
\hline Seis ciclos & $13,2-13,9$ \\
\hline Sete ciclos & $13,7-14,2$ \\
\hline Sete ciclos (pellet) & $14,7-14,8$ \\
\hline
\end{tabular}

Para determinar a CTC após a titulação (valores gastos encontram-se na Tabela 5) utilizou-se a seguinte equação:

$$
\operatorname{CTC}\left(\operatorname{mmol} \mathrm{kg}^{-1}\right)=\frac{1000 \cdot M\left(V_{a}-V_{b}\right)}{G}
$$

Os valores encontrados são aceitáveis (Tabela 10), dentro dos valores permitidos pela legislação pertinente (BRASIL-MAPA) que é uma CTC mínima de 80 mmolc $\mathrm{kg}^{-1}$. O valor de CTC indica o quanto um solo pode reter cátions em forma trocável, assim quanto maior a CTC do adubo aplicado, maior sua contribuição para o poder de retenção de cátions em forma trocável do solo, evitando assim maiores perdas de nutrientes por lixiviação (KIEHL, 2004).

Tabela 5: Valores de CTC encontrados nos diferentes ciclos da cama de frango.

\begin{tabular}{l|l}
\hline \hline AMOSTRA & CTC $\left(\mathbf{m m o l} \mathbf{~ K g}^{-1}\right)$ \\
\hline \hline Cinco ciclos & $500-509$ \\
\hline Seis ciclos & $469-500$ \\
\hline Sete ciclos & $491-514$ \\
\hline Sete ciclos (pellet) & $536-540$ \\
\hline \hline
\end{tabular}

\section{Testes agronômicos}

Os resultados obtidos pela caracterização físico-química são muito bons, apresentando sempre valores próximos aos exigidos pela legislação e na maioria corroborando com os dados da literatura se mostrando de início com um ótimo potencial agronômico, mesmo sem ter passado por processos de compostagem. Entretanto apenas resultados em teores de nutrientes (caracterização físico-química) não bastam para se avaliar, mesmo que inicialmente, a atividade agronômica de um material, é essencial avaliar 
qual o desenvolvimento de uma cultura frente a adubação com o mesmo. Assim a seguir, serão apresentados os resultados obtidos em testes agronômicos elaborados com o cultivo da cultura do milho frente à adubação com cama de frango.

Os sistemas elaborados para os testes de germinação e desenvolvimento inicial foram extremamente simples. Na falta da casa de vegetação, as sementes foram plantadas em copos descartáveis contendo aproximadamente $45 \mathrm{~g}$ de vermiculita expandida.

Cada um dos lotes possuía três sistemas distintos, entretanto, os três sistemas de cada lote possuem a mesma concentração de adubos (orgânico e mineral), ou seja, os três sistemas do 10 lote utilizam uma concentração $X$ de adubo e os três sistemas do 2 일 lote possui uma concentração $Y$ de adubo.

Sistema 1 (primeiro lote): $\pm 45 \mathrm{~g}$ de vermiculita expandida $+1 \mathrm{~g}$ de adubo orgânico.

Sistema 2 (primeiro lote): $\pm 45 \mathrm{~g}$ de vermiculita expandida $+1 \mathrm{~g}$ de adubo mineral.

Sistema 3 (primeiro lote): $\pm 45 \mathrm{~g}$ de vermiculita expandida $+1 \mathrm{~g}$ de adubo orgânico cinco dias após a germinação (adubação a lanço).

Sistema 1 (segundo lote): $\pm 45 \mathrm{~g}$ de vermiculita expandida $+0,4 \mathrm{~g}$ de adubo orgânico.

Sistema 2 (segundo lote): $\pm 45 \mathrm{~g}$ de vermiculita expandida sem adubo.

Sistema 3 (segundo lote): $\pm 45 \mathrm{~g}$ de vermiculita expandida $+0,4 \mathrm{~g}$ de adubo mineral.

O adubo orgânico utilizado estava na forma peletizada, constituído a partir da cama de frango in natura com sete ciclos de criação de aves. O número de ciclos foi escolhido com base nos resultados da caracterização da cama com diferentes ciclos, onde os resultados mostram que a cama com sete ciclos apresenta maior concentração dos nutrientes NPK, sendo a mais adequada para a produção do pellet, visto que no processo de produção há algumas perdas principalmente de $\mathrm{N}$, muito provável pela alta temperatura alcançada no processo.

\section{Primeiro Lote}

O sistema 1 apresentou melhor índice de germinação e desenvolvimento inicial em relação aos outros dois sistemas (2 e 3). A diferença de concentração do adubo orgânico para o mineral é acentuada, com um adubo orgânico com aproximadamente $4 \%$ de $\mathrm{N}$, em vista do produto mineral contém $10 \%$ do mesmo nutriente. Restringe-se a discutir em um primeiro momento sobre os teores do $\mathrm{N}$, por este ser o nutriente de maior participação no desenvolvimento do milho.

Quando se utilizou a mesma quantidade dos adubos, o mineral, com maior concentração NPK, passou a ser tóxico. 0 terceiro sistema foi um intermediário, não teve um bom desenvolvimento como o sistema 1 porém em relação ao sistema 2 obteve um melhor desenvolvimento. As Figuras 2 e 3 apresentam estes sistemas após sete dias e vinte e sete dias.

O baixo desenvolvimento do sistema 3 em relação ao sistema 1, pode ter relação com a perda por volatilização de $\mathrm{N}$ no meio, já que a adubação superior pode favorecer esse processo, assim como um possível atraso da atividade microbiana, que leva à um retardamento na absorção do N pela planta. Segundo Brady (1989) grande parte do nitrogênio adicionado ao solo passa por várias transformações, antes de sua remoção, 
o nitrogênio orgânico passa por vários processos de modificação muito complexos e alguns deles podem levar a diminuição dos teores de nitrogênio disponíveis no solo, tais como a lixiviação e a volatilização.

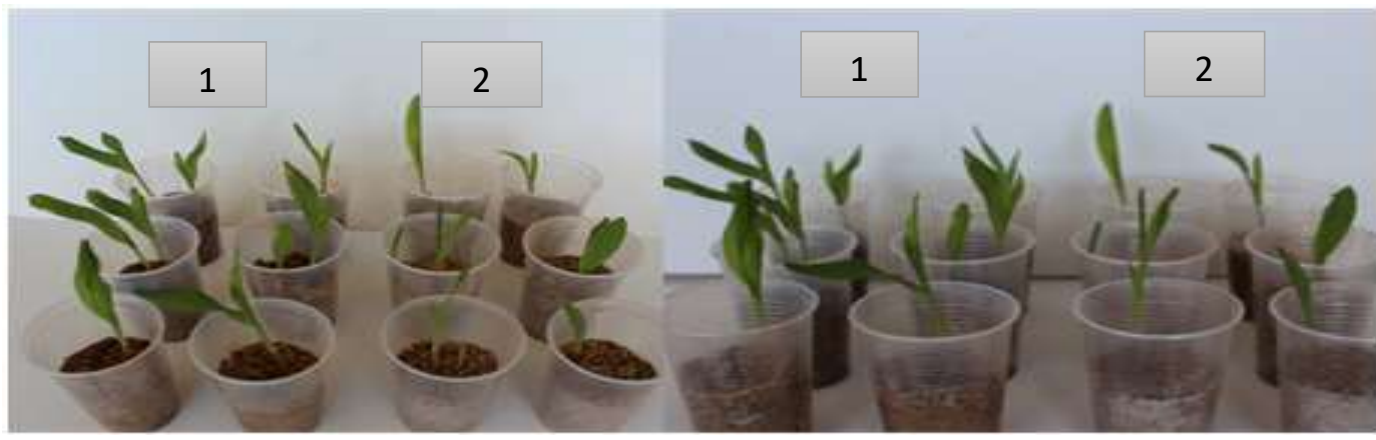

Figura 2: Germinação (sete dias) dos sistemas 1 e 2.

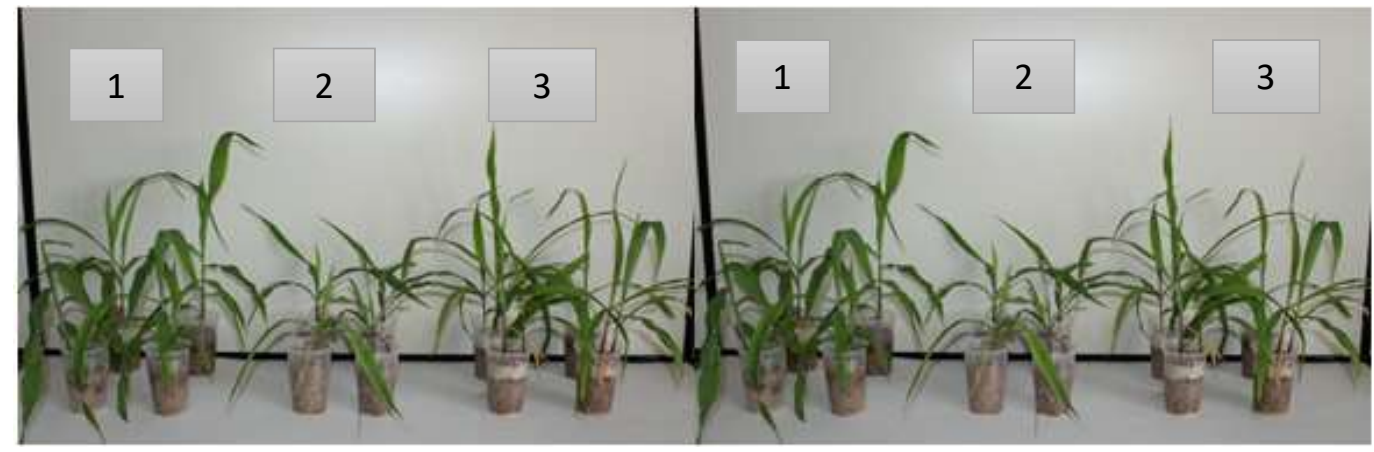

Figura 3: Desenvolvimento inicial (vinte e sete dias) dos sistemas 1,2 e 3.

Durante os processos microbiológicos envolvendo a decomposição dos resíduos animais ou vegetais, em especial os que apresentam menores quantidades de $\mathrm{N}$, ocorre a conversão para a forma orgânica de quase todo nitrogênio inorgânico do solo, que basicamente vira tecido microbiano. Assim que a atividade microbiana vai diminuindo, parte do $\mathrm{N}$ que foi imobilizado será mineralizado e os íons amônio e nitrato aparecerão novamente no solo, entretanto apenas uma pequena parte desses $\mathrm{N}$ imobilizados passará para a forma inorgânica, permanecendo em maioria na forma orgânica (BRADY, 1989). Assim, a mineralização do nitrogênio orgânico compõe o primeiro passo para a sua disponibilidade em forma assimilável.

O processo de nitrificação pode ser definido como a formação biológica de nitrato ou nitrito a partir de compostos que contenham nitrogênio na forma amoniacal $\left(\mathrm{NH}_{4}^{+}\right)$. A importância dos nitrificantes está no fato da produção de nitrato, que a principal fonte de nitrogênio assimilado pelas plantas. A nitrificação é um processo de oxidação enzimática da amônia para nitrato, originado por micro-organismos do solo, ocorre em duas fases, um grupo específico de micro-organismos forma os íons nitritos que de imediato são oxidados e outro grupo faz a formação dos nitratos. Tal processo apresenta maior eficiência em solos com pH tendendo a alcalinidade (BRADY, 1989; KIEHL, 2004).

Quando ocorre o processo de desnitrificação, redução dos nitratos a nitrogênio elementar na forma gasosa desencadeia-se uma grande perda desse nutriente para a atmosfera.

Assim como o N, o P tem grande importância na atividade agrícola, e é um dos componentes que abrange as mais importantes transformações energéticas nos vegetais, entretanto, sua maior participação no desenvolvimento do milho (Zea mays) fica no estágio da floração e desenvolvimento das espigas, fato que 
nos restringe aqui, a discussão de sua influência no desenvolvimento inicial da cultura. Mesmo não sendo requerido em altas quantidades no desenvolvimento inicial como o N, o P necessita de uma faixa específica de pH para sua máxima assimilabilidade, segundo Brady (1989) a máxima assimilabilidade do P é obtida com a manutenção do pH do solo na faixa de 6 a 7. A neutralidade da vermiculita juntamente com a cama de frango ligeiramente alcalina, proporcionou um substrato final (solo) com uma faixa de $\mathrm{pH}$ muito próxima dos dados da literatura indicados para uma máxima assimilabilidade do $P$.

\section{Segundo Lote}

O segundo lote apresentou um desenvolvimento mais linear entre adubo orgânico e adubo mineral. O fato de o adubo orgânico apresentar concentrações bem menores de NPK em relação ao adubo mineral pode explicar a pequena diferença de desenvolvimento no cultivo do milho. Entretanto mesmo com uma pequena desvantagem em relação ao adubo mineral, o adubo orgânico se apresenta com uma ótima atividade agronômica, quando comparamos o desenvolvimento do sistema 1 em relação ao sistema 2 (sem aplicação de adubo). As Figuras 4 e 5 apresentam estes sistemas após sete dias e vinte e dois dias.

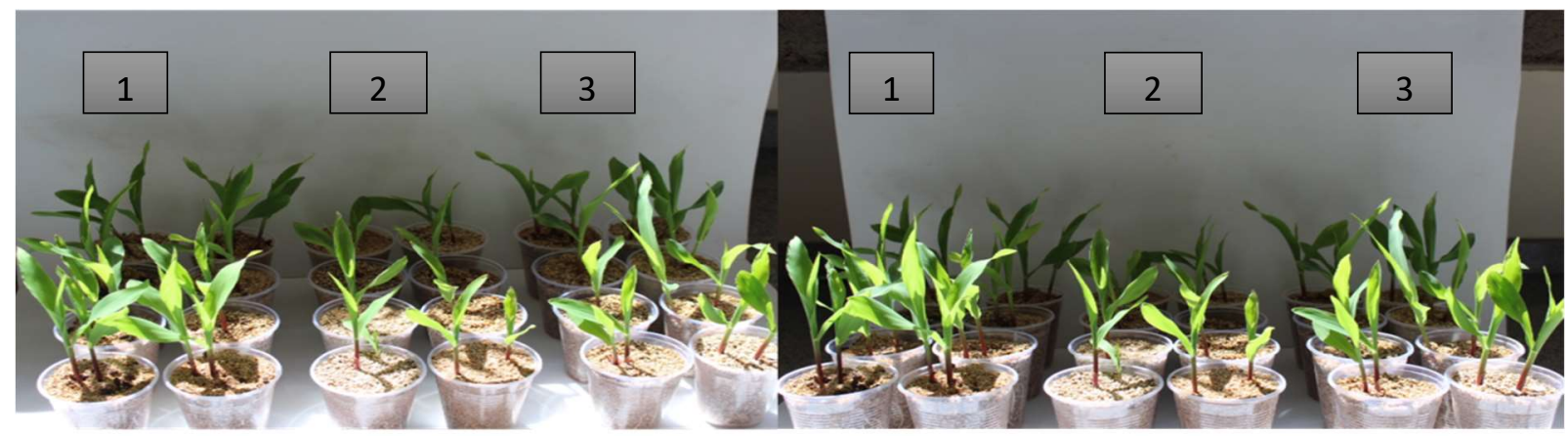

Figura 4: Germinação (sete dias) dos sistemas 1,2 e 3.

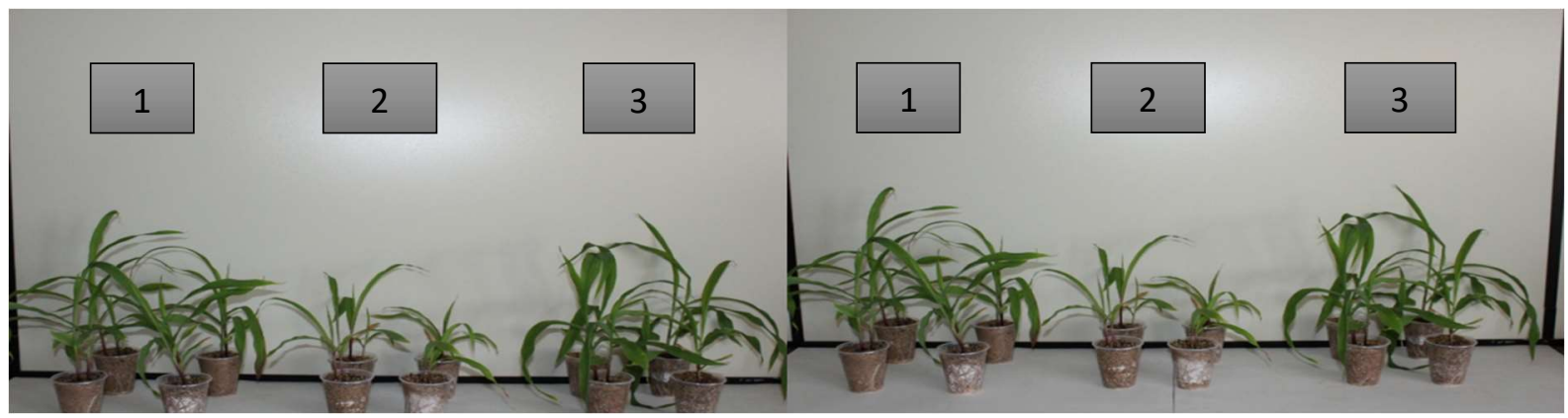

Figura 5: Desenvolvimento inicial (vinte e dois dias) dos sistemas 1,2 e 3.

\section{Avaliação da absorção dos macronutrientes NPK pela cultura do milho}

O desenvolvimento do milho é dividido em várias etapas. O estágio de maturação é onde a planta mais requer os nutrientes, sejam eles $\mathrm{N}, \mathrm{P}$ ou K, conseguinte as plantas utilizadas para realização de análise foliar adequada se encontram nesse estágio de desenvolvimento. Avaliar o estado nutricional de uma planta consiste em fazer uma comparação entre uma amostra e um padrão. Amostra é uma planta ou um conjunto de plantas. O padrão consiste em uma planta ou um conjunto de plantas 'normais' do ponto de vista da sua nutrição. É considerada normal uma planta que possui seus tecidos com todos os elementos em quantidades 
e proporções adequadas, capazes de dar altas produções, tendo um aspecto visual parecido com o encontrado em lavouras muito produtivas (MALAVOLTA, 1997).

Segundo Malavolta (1997) os teores adequados de NPK (análise de folhas) para a cultura do milho é de $27,5-32,5 ; 2,5-3,5$ e 17,5-22,5 g/gk respectivamente, tais valores não podem ser utilizados como referência para a análise de absorção de nutrientes realizada neste trabalho, visto que, os estágios em que se encontram as plantas para análise são diferentes. Os dados apresentados pela literatura são de plantas em estágio de maturação, já os resultados apresentados no trabalho são de plantas em estágio inicial de desenvolvimento, vinte e dois e vinte e sete dias de crescimento. Neste contexto os resultados apresentados a seguir podem subsidiar informações para uma análise prévia do potencial de adubação da cama de frango peletizada não compostada.

\section{Determinação de Nitrogênio Total}

Os teores de nitrogênio obtidos pela análise foliar da cultura do milho foram determinados utilizando a equação a seguir.

$$
N-N_{4} g k^{-1}=\left(V_{b}-V_{a}\right) .1,4
$$

Os resultados obtidos que se encontram reunidos na Tabela 6 mostraram-se satisfatórios, pois todos os sistemas de cultivo contendo cama de frango peletizada apresentaram maiores teores de $\mathrm{N}$ na análise foliar quando comparados aos sistemas contendo adubo mineral. Os resultados mostram a boa atividade agronômica da cama e ainda nos permite concluir algumas possibilidades sobre modo de aplicação e influência nas perdas de nutrientes, visto que o sistema 3 do primeiro lote mesmo com a mesma concentração de adubo orgânico apresentou menor desenvolvimento e menor absorção de nutrientes pela planta em comparação com o sistema 1, esse fator pode ter tido influência pela facilidade de perdas de $\mathrm{N}$ por volatização visto que a prática de adubação utilizada foi superior (a lanço), nessa prática o adubo fica exposto a superfície, quando o $\mathrm{N}$ se apresenta na forma de gás, se perde na atmosfera. Quando o mesmo se encontra incorporado no solo, em condições ideais, quando entra em forma de gás, ainda pode dentro do ciclo do nitrogênio passar para a forma assimilável, diminuindo as perdas por volatização. Ou ainda uma possível atividade de micro-organismo atrasada, na decomposição do C, por conseguinte, pode ter atrasado a disponibilidade de $\mathrm{N}$ para a planta, diminuindo seu desenvolvimento.

Tabela 6: Valores de Nitrogênio determinados pela análise foliar.

\begin{tabular}{|c|c|}
\hline AMOSTRA & $\mathrm{N}-\mathrm{NH}_{4}\left(\mathrm{~g} \mathrm{~kg}^{-1}\right)$ \\
\hline Sistema 1(10 lote) & $2,38-3,22$ \\
\hline Sistema 2(1익 lote) & $0,2-0,5$ \\
\hline Sistema 3(1ㅇlote) & $0,98-1,12$ \\
\hline Sistema 1 (2ㅇ lote) & $3,2-3,5$ \\
\hline Sistema 2(2ㅇ lote) & $0,9-1,3$ \\
\hline Sistema 3 (2ㅇ lote) & $0,2-0,7$ \\
\hline
\end{tabular}

O segundo lote apresentou resultados que se contradizem com a análise visual realizada com os testes de germinação e desenvolvimento inicial, visto que o $\mathrm{N}$ é o principal nutriente responsável pelo crescimento da planta em seus estágios iniciais, em estágios posteriores $\mathrm{K}$ e $\mathrm{P}$ tem influencias maiores. $\mathrm{O}$ 
sistema 1 composto por adubação orgânica apresentou uma ligeira inferioridade no seu desenvolvimento em relação ao sistema três, adubado com adubo mineral, com maiores concentrações de NPK, entretanto os resultados da análise foliar, determinação de $\mathrm{N}$, são maiores do que os resultados obtidos da análise realizada no sistema três, que apresenta melhor desenvolvimento no teste agronômico.

\section{Determinação de Fósforo Total (P)}

Os resultados para o $\mathrm{P}$ encontrados após a análise foliar foram relativamente baixos. Isso ocorreu, possivelmente devido a dois principais fatores, primeiro essa cultura em específico absorve ou requer esse nutriente na fase de maturação e a análise foi realizada com plantas em estágio inicial de desenvolvimento. O segundo é a especificidade de faixa de pH entre 6.0 e 7,0 que o fósforo requer para se encontrar na forma assimilável. Pode-se observar na Tabela 7, que apenas o sistema 1 do primeiro lote e sistema 3 do segundo lote encontram-se dentro desta faixa, fator que pode ter diminuído ainda mais a absorção do $\mathrm{P}$ pela cultura.

Tabela 7: Valores de $\mathrm{pH}$ encontrados no solo (vermiculita) utilizado para plantio.

\begin{tabular}{l|l}
\hline \hline AMOSTRA & pH \\
\hline \hline Sistema 1(1ㅇle) & $6,14-6,32$ \\
\hline Sistema 2(1ㅇole) & $7,34-7,49$ \\
\hline Sistema 3(1ㅇole) & $7,57-7,89$ \\
\hline Sistema 1(2o lote) & $7,97-8,54$ \\
\hline Sistema 2(2ㅇote) & $7,31-7,98$ \\
\hline Sistema 3(2o lote) & $6,85-7,23$ \\
\hline \hline
\end{tabular}

A Figura 6 apresenta a curva de calibração obtida a partir da análise na espectroscopia de ultravioletavisível utilizada para a determinação do $P$ na análise foliar, cujo coeficiente de correlação é 0,9945 . As concentrações de P observadas encontram-se reunidas na Tabela 8.

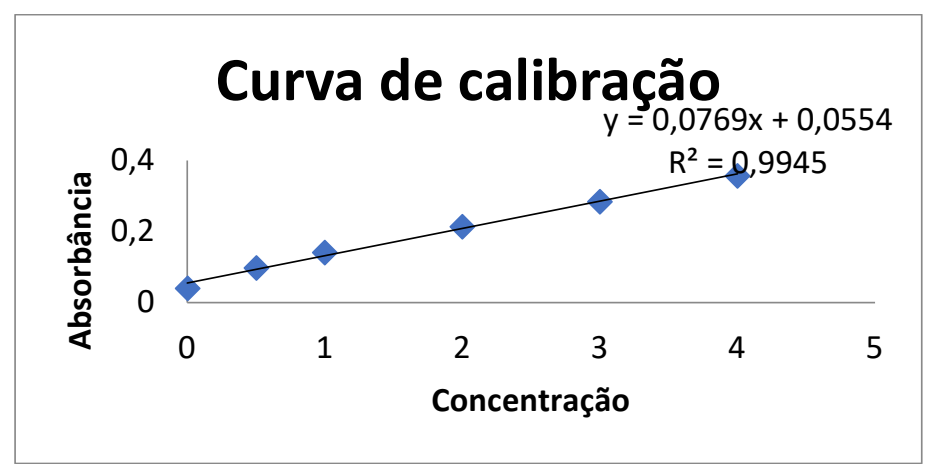

Figura 6: Curva de calibração utilizada para determinação de P na análise foliar.

Tabela 8: Concentração de fósforo encontrada na análise foliar.

\begin{tabular}{|c|c|}
\hline Amostra & $\mathrm{P}\left(\mathrm{mg} \mathrm{kg}^{-1}\right)$ \\
\hline Sistema 1(1이이 lote) & $0,34-0,36$ \\
\hline Sistema 2(1이이 lote) & $0,0-0,06$ \\
\hline Sistema 3(1이이 lote) & $0,07-0,1$ \\
\hline Sistema 1(2ㅇote) & $0,06-0,09$ \\
\hline Sistema 2(2ㅇ lote) & $0,0-0,05$ \\
\hline Sistema 3(2ㅇ lote) & $0,1-0,2$ \\
\hline
\end{tabular}

\section{Determinação de Potássio.}

Os teores de potássio determinados na análise foliar apresentaram-se bem abaixo do esperado 
quando relacionados com os teores encontrados na literatura $\left(17,5-22,5 \mathrm{mg} \mathrm{kg}^{-1}\right)$ e ainda considerando os graus de desenvolvimento, já que a análise neste trabalho foi realizada em tempo diferente do mais adequado, determinado pela literatura. Uma das possíveis causas da enorme diferença nas concentrações é a possível fixação de íons potássio na presença de vermiculita.

A Figura 7 apresenta a curva de calibração obtida a partir da análise na espectrometria de absorção atômica utilizada para a determinação do K na análise foliar. As concentrações de K observadas encontramse reunidas na Tabela 9.

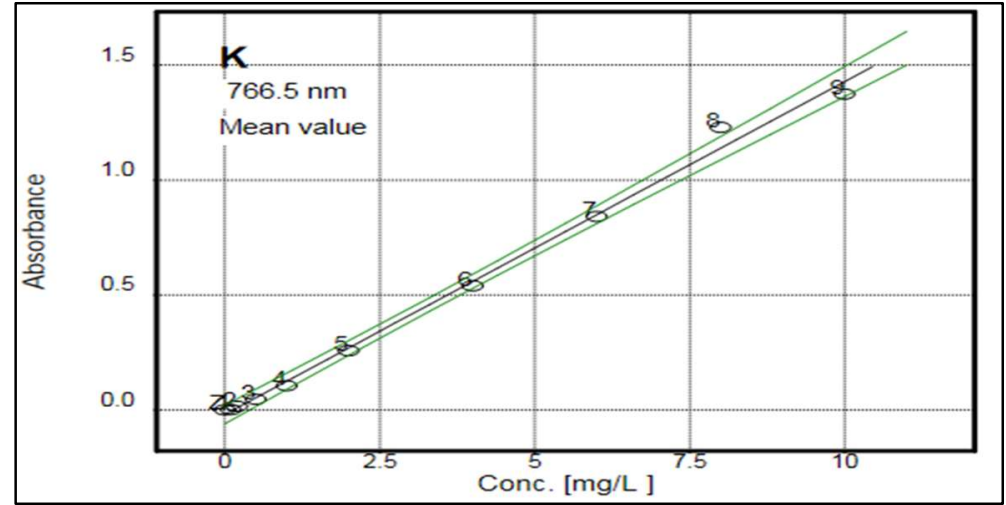

Figura 7: Curva de calibração utilizada para determinação de $\mathrm{K}$ na análise foliar.

Tabela 9: Concentração de K encontrada na análise foliar.

\begin{tabular}{l|l}
\hline \hline AMOSTRA & $\mathbf{K} \mathbf{( \mathbf { m g ~ } ^ { - 1 } \mathbf { ) }}$ \\
\hline \hline Sistema 1(1ㅇ lote) & $428-433$ \\
\hline Sistema 2(1ㅇ lote) & $443-450$ \\
\hline Sistema 3(10 lote) & $227-238$ \\
\hline Sistema 1(2o lote) & $228-229$ \\
\hline Sistema 2(2o lote) & $64-65$ \\
\hline Sistema 3(2o lote) & $212-215$ \\
\hline \hline
\end{tabular}

Mesmo apresentando grande diferença, devido principalmente aos tempos de desenvolvimento da cultura, a análise foliar apresentou bons resultados, confirmando a boa atividade agronômica da cama de frango não compostada, posteriormente estudos de desenvolvimento agronômico são necessários em solos tradicionais.

\section{CONCLUSÕES}

O estudo de viabilização da utilização de cama de aviário peletizada não compostada, apresentou resultados satisfatórios. A caracterização físico-química da cama de frango com cinco, seis e sete ciclos de criação de aves in natura, mais o pellet, constituído a partir da cama com sete ciclos in natura apresentaram bons resultados, sempre próximos aos valores apontados pela legislação (BRASIL-MAPA) e a partir deles determinou-se o quantitativo de ciclos de criação mais adequado para se utilizar na produção do pellet.

Após a caracterização do material partiu-se para a etapa de testes agronômicos, com avaliação de germinação e desenvolvimento inicial do cultivo do milho e avaliação da absorção dos nutrientes (análise foliar). Os resultados ficaram dentro do esperado, o produto no geral apresentou boa atividade agronômica, os sistemas elaborados com adubação orgânica (cama de frango) apresentaram desenvolvimento muito 
próximo ao desenvolvimento dos sistemas elaborados com adubação mineral.

Neste contexto o estudo executado expõe de forma positiva a utilização da cama de frango peletizada não compostada como adubo orgânico. Entretanto estudos posteriores são necessários, tais como análise de patógenos e metais traços, para uma maior segurança no estudo de viabilização de utilização do produto $\mathrm{O}$ estudo ainda abre portas para o desenvolvimento, de complementação desse produto, com finalidade de otimizar o quantitativo de aplicação do mesmo com criação de mecanismo de liberação controlada a fim de diminuir as perdas por lixiviação.

\section{REFERÊNCIAS}

BENITES, V. M.; CORREA, J. C.; MENEZES, J. F. S.; POLIDORO, J. C.. Produção de fertilizante organomineral granulado a partir de dejetos de suínos e aves no Brasil. In: REUNIÃO BRASILEIRA DE FERTILIDADE DE SOLO E NUTRIÇÃO DE PLANTA, 29. Anais. Guarapari: FERTBIO, 2010.

BELTRAME, K. K.. Avaliação dos métodos Walkley \& Black e CHN como métodos de referência para calibração multivariada na determinação de carbono orgânico em solos brasileiros. Monografia (Bacharelado em Licenciatura em Química) - Universidade Tecnológica Federal do Paraná, Curitiba, 2014.

BUENO, P.; TAPIAS, R.; LÓPEZ, F.; DÍAS, M. J.. Optimizing composting parameters for nitrogen conservation in composting. Bioresource Technology, v.99, p.5069-5077, 2008.

BRADY, M. C.. Natureza e Propriedades dos Solos. 7 ed. Rio de Janeiro: Freitas Bastos, 1989.

FAQUIN, V.. Nutrição Mineral de Plantas. Monografia (Especialização em à Distância Solos e Meio Ambiente) Universidade Federal de Lavras, Lavras, 2005.

HARRIS, D. C.. Análise química quantitativa. 8 ed. Rio de Janeiro: LTC, 2012.

HERNANDES, R.; CAZETTA, J. O.; MORAES, V. M. B.. Frações Nitrogenadas, Glicídicas e Amônia Liberada pela Cama de Frangos de Corte em Diferentes Densidades e Tempos de Confinamento. Revista Brasileira de Zootecnia, v.31, n.4, p.1795-1802, 2002.

KIEHL, E. J.. Manual de compostagem: maturação e qualidade do composto. Piracicaba. 4 ed. 2004.

LACEY, R. E.; MUKHTAR, S.; CAREY, J. B.; ULLMAN, J. L.. A review of literature concerning odors, ammonia, and dust from broiler production facilities: 1 . Odor concentrations and emissions. Journal of Applied Poultry Research v.13, p.500-508, 2004.

LANA, M. C.. Análise química de solo e tecido vegetal: práticas de laboratório. Marechal Cândido Rondon: Unioeste, 2009
LIMA, J. J.; MATA, J. V. D.; PINHEIRO NETO, R.; SCAPIM, C. A.. Influência da adubação orgânica nas propriedades químicas de um Latossolo Vermelho distrófico e na produção de matéria seca de Brachiaria brizantha cv. Marandu. Acta Scientiarum Agronomy, Maringá, v.29, p.715719, 2007.

MALAVOLTA, E.. Manual de calagem e adubação das principais culturas. São Paulo: Ceres, 1987.

MALAVOLTA, E.. Princípios, métodos e técnicas de avaliação do estado nutricional. In: Avaliação do estado nutricional das plantas: princípios e aplicações. 2 ed. Piracicaba: POTAFOS, 1997. p.115-230.

ORRICO JÚNIOR, M. A. P.; ORRICO, A. A.; LUCAS JÚNIOR, J.. Compostagem dos resíduos da produção avícola. Engenharia Agrícola, Jaboticabal, v.30, n.3, p.538-545, 2010.

OVIEDO-RONDÓN, E. O.. Tecnologias para mitigar o impacto ambiental da produção de frangos de corte. Revista Brasileira de Zootecnia, Raleigh, v.37, p.239-252, 2008.

PIRES, A. M. M.; MATTIAZZO, M. M.. Avaliação da viabilidade do uso de resíduos na agricultura. Circular Técnica, 19. Jaguariúna: Embrapa Meio Ambiente, 2008.

ROBARGE, W. P.; MCCULLOCH, R.; CURE, W.. Atmospheric concentrations of ammonia and ammonium in the vicinity of animal production facilities in eastern North Carolina. In: PROCEEDINGS OF 1999 ANIMAL WASTE MANAGEMENT SYMPOSIUM. Anais. Cary, 1999. p.365-371.

RODRIGUES, W. O. P.; GARCIA, R. G.; NÄÄS, I. A.; ROSA, C. O.; CALDARELLI, C. E.. Evolução da avicultura de corte no Brasil. Dourados: Enciclopédia Biosfera-Centro Científico Conhecer, 2014.

SEIFFERT, N. F.. Planejamento da atividade avícola visando qualidade ambiental. In: SIMPÓSIO SOBRE RESÍDUOS DA PRODUÇÃO AVÍCOLA. Anais. Concórdia, 2000. p.1-20.

SKOOG, D. A.; HOLLER, F. J.; CROUCH, S. R.. Princípios de análise instrumental. 6 ed. Porto Alegre: Bookman, 2009.

TERZICH, M.; POPE, M. J.; CHERRY, T. E.; HOLLINGER, J.. Survey of pathogens in poultry litter in the United States. 
Journal of Applied Poultry Research, v.9, n.2, p.287-291, 2000.

WILLIAMS, C. M.; BARKER, J. C.; SIMS, J. T.. Management and utilization of poultry wastes. Reviews of Environmental Contamination and Toxicology, v.162, p.105-157, 1999.
ZHONGCHAO, T.; ZHANG, Y.. A review of effects and control methods of particulate matter in animal indoor environments. Air and Waste Management Association, v.54, p.845-854, 2004

A CBPC - Companhia Brasileira de Produção Científica (CNPJ: 11.221.422/0001-03) detém os direitos materiais desta publicação. Os direitos referem-se à publicação do trabalho em qualquer parte do mundo, incluindo os direitos às renovações, expansões e disseminações da contribuiç̃o, bem como outros direitos subsidiários. Todos os trabalhos publicados eletronicamente poderão posteriormente ser publicados em coletâneas impressas sob coordenação da Sustenere Publishing, da Companhia Brasileira de Produção Científica e seus parceiros autorizados. Os (as) autores (as) preservam os direitos autorais, mas não têm permissão para a publicação da contribuição em outro meio, impresso ou digital, em português ou em tradução. 